is offered in the hope of saving life. There is little wonder that our profession should supply a shorter average of life than any other. Alone, the medical man is never allowed to be ill and he is singular in continuing to work whilst ill. No other profession claims that its labour shall be carried on at night and on holidays and to this must be added the constant exposure to infection and to other risks. But it is not sufficiently realised that the work done by the profession in saving the life of individuals and in checking the spread of disease is a direct service and a direct gain to the State. Has its practical value been fully recognised? We enjoy, it is true, and are thankful for the favour and the protection of the State. But beyond charters and privileges such as are granted to great commercial associations working for their own profit and only indirectly for their fellow creatures and for the State little has been bestowed upon us. On the basis of this service we might as a profession be in a position to treat with the State. This was the custom with the ancient guilds. No such bargain has ever been submitted from our side. Men of medicine have parted with their "mystery" without even thinking of an equivalent which has not been proposed from the other side in the shape of any practical recognition. Whilst other professions act on the principle "Do ut des" the fruits of medical science which prosper our days of peace and ensure the success of our wars are a free gift to the State. And that profession which alone shares with the Church the direct care for the welfare of the community has little share in its honours.

The deserts of the profession.-Yet having regard to the value which the individual sets upon his own life, to the actual value which lives saved represent to the State and to the untold boon to humanity in the alleviation of suffering it is difficult to see what recognition could be adequate. In a younger world with such a record healers of the sick would have walked as gods among men. From the individual the medical attendant receives an honorarium only in acknowledgment of a debt which cannot be entirely paid. By the State this acknowledgment of debt is hardly made and the honorarium is scantily bestowed though statesmen admit that without a healthy population there can be no national greatness.

The place of medicine among professions. - Precedence between professions and their social status are regulated by custom and there is no desire among us to disturb these ancient traditions. It may be said of all professions that they have risen in dignity. In the case of medicine the rise in worth as estimated in vastly increased knowledge, in usefulness as judged from the amount of human life saved, and in influence as regards the practical reforms administered by the State under our guidance has been out of all proportion to any position which it has ever held. The end of the last century witnessed a revolution in France which brought to the front tumultuously the social layers by whom the chief work of the world had been carried on without recognition. Less turbulently but with unfaltering step medicine has been marching towards its proper place in the front rank of the professions. What is the medical profession in the State? Nothing. What should it be? The chief and most important influence. For it was truly said: "Sanitas sanitatum, omnia sanitas."

The reward: its deeds and ils dignity.-.The power silently wielded by our profession is ever increasing and must give it importance and ultimately a foremost position. For the present its reward lies in the consciousness of this fact, imperfectly realised by our fellow men; and also in its dignity, in its intellectual work, and in a knowledge that its ministrations are indispensable as well as beneficent. In this isolation and this consciousness of power there is a superiority. The profession if a self-made aristocracy of usefulness whose distinction is not exclusiveness but the widest sympathy, whose strength is not privilege but prodigal self-sacrifice. Let the estimate placed upon it by its members never fall beneath its great aims and achievements. Our part as its representatives is one of increasing loyalty and self-dignity. This duty lies before each of us and its fruits are within our own grasp as may be seen by the success of combined action of the profession whenever it has been attempted. In addition to Pandora's legacy to our race there is for our profession a large inheritance of charity as well as of faith in the progress of humanity and in its own destinies. These things that we see and know cannot much longer escape the notice of the people and of their leaders.

\section{NOTES OF THREE CASES OF PERFORATED GASTRIC ULCER SHOWING COMPLI- CATIONS AFTER OPERATION,}

ONE CASE ILLUSTRATING A NEW SURGICAL METHOD OF* TREATING SEVERE RECURRENT H FMORRHAGE FROM GASTRIC ULCERS.

By WILLOUGHBY FURNER, F.R.C.S. ExG., M.D. DuRH. SURGEON TO THE SUSSEX COUNTY HOSPITAL.

THE chief or primary complications of gastric ulcers-viz., perforation, hæmorrhage, and subphrenic abscess-are also met with as complications following an apparently successful operation for the cure of perforated ulcers. After reading the notes of the cases I will offer for consideration in the course of my subsequent remarks two suggestions which have occurred to me-one for the treatment of severe recurrent hæmorrhage from gastric ulcers and the other for the adoption of additional precautions against the formation of retro-gastric subphrenic abscess after operation.

CASE 1.- The patient, a female, aged thirty-seven years, was suddenly seized whilst attending to her duties on May 24th, 1895, with severe abdominal pains. I saw her five hours later and found her somewhat recovered from collapse but with signs of general peritonitis. She said that she had suffered for a long time from indigestion and pain in the pit of the stomach. Vomiting, not especially soon after food, but at any time, began some weeks earlier. On opening the abdomen in the epigastric region a large abscess containing foul-smelling pus was found leading directly into the stomach. "The wall of the abscess was also deficient at the lower part and it was evident that here there was a rupture into the general peritoneal cavity. A second incision was made above the pubes and both the abscess cavity and the general peritoneal cavity were thoroughly flushed. The abscess cavity was lightly packed with gauze drain and a drainage-tube was inserted above the pubes. The patient did well at first, the peritonitis subsiding, and at the end of seven days she was removed to the Sussex County Hospital where she remained for a fortnight longer, but the epigastric wound showed no signs of healing. All fluids which were swallowed ran out directly through the wound which became septic and the patient died on June 13th from exhaustion, three weeks from the date of rupture. I had left the town for a holiday on June 1st and I learnt the final details of the case on my return. The necropsy showed, as I was informed, the stomach to be contracted and adherent to the adjacent viscera, but there was no malignant disease. The patient died worn out with hectic and inability to retain food. I have since thought that I might have prolonged her life by performing the operation which I will describe later.

CASE 2.-The patient was a female, aged twenty-two years. She was admitted into the Sussex County Hospital on April 1st, 1898, with symptoms of ruptured gastric ulcer. She had suffered for about five years from anæmia and from pain after food referred chiefly to the cardiac end of the stomach. For some months she had been subject to vomiting after food but there was never any blood. On March 31st, when running upstairs before dinner, she was seized suddenly with severe pain in the left side of the abdomen and epigastrium. On admission, twenty-four hours later, she was still somewhat collapsed; the abdomen was distended and hard but there was no liver dulness. On opening the abdomen gas escaped but no stomach contents were visible in the peritoneal cavity. The stomach was empty, showing on the anterior surface of the lesser curvature close to the cardiac end an indurated surface about $3 \mathrm{~cm}$. in diameter in the centre of which was a tear about $1 \mathrm{~cm}$. in length. The stomach walls were folded over the induration and were stitched together by one row of Lembert's sutures. The peritoneal cavity was washed out with saline fluid and a gauze drain was left in the epigastric wound. The patient did well in spite of frequent vomiting during the first twentyfour hours till April 12th when the temperature rose to $101^{\circ} \mathrm{F}$. There was no rigor and no pain and the respirations

1 A paper read before the Brighton and Sussex Medico-Chirurgical Society on Nov. 3rd, 1898, with paragraphs added referring to case simulating perforations and those on the technique of the operations. 
were 32 per minute. Examination of the chest showed skodaic resonance over the left infra-clavicular region and dulness on the same side posteriorly over the base of the left lung. There was evidently a rapidly formed pleural effusion. On Apri? 16th, the temperature being then $102^{\circ}$, the left pleural cavity was aspirated and 400 c.c. of clete fluid were withdrawn. After this the patient gradually improved and was discharged well with no pain after food on July 3rd. When seen two months later she had gained flesh and was well in all respects and showed no evidences of phthisis. The object in tapping the left chest at such an early date was to determine as soon as possible whether the fluid was purulent or not; if purulent there would have been stronger recuson to suspect some irritation of the peritoneum, perhaps that of the lesser cavity which lies in relation with the posterior portion of the under surface of the diaplragm on the left side.

CASE 3.- The patient, a female, aged twenty-four years, was admitted into the Sussex County Hospital on Feb. 22nd. 1898, with symptoms of perforated gastric ulcer of four iours' duration. (She had been in the hospital for a few days in December, 1897, complaining of pain after food and nausea and she was then discharged feeling better.) For some time past the pain after food had been acute, coming on from half an hour to an hour after a meal, and was relieved by vomiting; there was also pain at night when the stomach was empty which was referred to the lower part of the sternum. There was no hæmatemesis. On Feb. 22nd after taking some bovril she was seized at once with acute pain in the epigastrium and with nausea but there was no vomiting. The patient was operated upon at 8.30 P.M., six and a half hours after the commencement of the symptoms. Perforation was found on the anterior surface of the lesser curvature about $2 \frac{1}{2} \mathrm{~cm}$. from the pylorus. The peritoneal cavity contained gaseous and other contents of the stomach. The valcer was closed by one row of Lembert's sutures and the peritoneal cavity was flushed with saline fluid and drained through the second opening above the pubes. Rectal feeding was followed for three days; then in addition small quantities of fluid food were given by the mouth, but as pain and flatulence followed feedig by the rectum only was resumed till Feb. 28th. On March 1st careful feeding with small quantities of milk and barley water by the mouth was again tried. There was no pain or flatulence. The patient passed a large, loose, black stool on the night of the 2 nd, another soon after with a returned nutrient enema, and a third on the next morning. Melæna was absent on the 4th but it returned on the 5th. The patient was blanched and restless; nutrient injections were not retained and the rectum was full of black clot. Feeding by the mouth being out of the question and as it seemed too hazardous to trust to drugs to check the bleeding I decided to open the small intestine with the view of feeding the patient whilst resting the stomach. An incision through the abdominal muscles was made near the right semilunar line in order to avoid the sites of the epigastric and pubic incisions not yet healed and a thick-walled portion of small intestine, ascertained by drawing it out of the abdomen to be distant at least a metre from the ileo-crcal valve and thought to be a good deal further, was opened and a small rubber tube was inserted; the intestine was fixed to the parietes. On the same evening the patient being very weak and restless after recovering from the anæsthetic was fed with 500 c.c. of peptonised milk through a tube in the intestine. A morphia suppository was administered per rectum. On the 6 th the patient was much better. 500 c.c. of peptonised milk were given through the tube every four hours. She had a rigor during the night. On the morning of the 8th the temperature was $104^{\circ} \mathrm{F}$. and the left parotid was swollen and tender; 25 c.c. of brandy were added occasionally to the food and 0.118 c.c. of solution of strychnine was given at each feeding. The morphia suppository was continued and a fomentation was applied to the parotid. On the 9 th the patient was better. The temperature was $98.8^{\circ}$ and the parotid was less swollen and not so painful. On the 12 th feeding by the mouth in small quantities was re-commenced and feeding through the tube in the intestine was continued. The patient was beginning to gain flesh and she had no pain. On the 22nd she was fed entirely by the mouth; from this date onwards convalescence continued, but as the wound in the intestine left a small sinus which leaked this was closed by operation on July 6 th and she left the hospital quite well with no pain after food on Sept. 9th. When seen six weeks later she was perfectly well.
Hæmorrhage after operation in any case similar to Case 3 , excluding other causes of hæmorrhage, may proceed from the ulcer which perforated and has been closed; from injury during the operation to a previously healthy portion of the stomach; or from a second ulcer coexistent. Statistics ${ }^{2}$ tell us that about 3 per cent. of cases of gastric ulcer die from hæmorrhage and that about $6 \frac{1}{2}$ per cent. of all cases perforate. Of those ulcers which perforate 36 per cent. are on the lesser curvature, 29 per cent. on the anterior surface, 9 per cent. on the pyloric end, 6 per cent. on the posterior surface, 5 per cent. on the cardiac end, and 2 per cent. on the middle of the stomach. In 13 per cent. there were two ulcers opposite to each other on the anterior and pôsterior surfaces of the stomach, the former being the site of the perforation while the latter was in most instances firmly adherent to the pancreas.

The above figures were collected prior to the time when operations for perforation were first performed. Quoting from more recent figures of gastric ulcers operated on at St. Mary's Hospital' Dr. Walter Broadbent tells us that out of 18 cases operated upon 3 cases had ulcers on the posterior wall as well, with their bases formed by the pancreas 2 others had an ulcer on the posterior wall only through the mucous membrane; and in 1 case a perforation occurred in an ulcer on the posterior surface after the anterior one $h$ ad been sewn up. In this list of all the cases which were operated upon one-third of the number had double ulcers. But whether a second ulcer is present or not, if grave symptoms such as perforation or hæmorrhage arise necessity for treatment is ur gent whatever be the cause.

If there be a second perforation, surgically speaking, the abdomen can be reopened and the perforation closed with or without a gastro-jejunostomy. Before deciding to interfere surgically at all it is well to bear in mind the details of two cases in which serious symptoms of perforation are recorded, yet in which no second perforation was found. One of these cases ${ }^{4}$ terminated fatally; no perforation existed and death was attributed to heart failure; in the other ${ }^{5}$ the abdomen was reopened and the patient recovered. In each case the original ulcer was on the posterior wall of the stomach and the proximity of the solar plexus to the necessary adhesions may help to explain the symptoms.

Passing to the complication of hæmorrhage it will be remembered that in Case 3 life was threatened by profuse gastric hæmorrhage a few days after operation. Nutrient enemata could no longer be retained; the rectum was filled with clots and the small intestines (as proved subsequently during the second operation) also contained a quantity of black blood. Treatment by drugs seemed hopeless; nutriment was urgently required. Before deciding upon the best surgical proceeding in a case such as this after operation it may be well to consider the recently suggested surgical treatment performed in a few cases of hæmorrhage following gastric ulcer which have not perforated and have not therefore been subjected to operation. Mr. W. Rose, ${ }^{6}$ writing on this subject in 1896, says: "Operations for hæmorrhage have not been frequent, indeed there are only two successful cases on record. Mikulicz performed one fatal operation and the two successful cases have occurred in the practice of Kuster." Dr. H. P. Hawkins ${ }^{7}$ mentions Kuster as quoting four cases of excision of gastric ulcer where life was threatened by hæmorrhage, of which three were successful. These are the only cases of operation for non-perforated gastric ulcer accompanied by bæmorrhage which I have hitherto been able to find. Dr. Hawkins quotes Leube as holding the opinion that operation should be performed not only where there are small and repeated hæmorrhages but also in a profuse hæmorrhage which is repeated. Leube reckons that in about 4 per cent. of all cases of non-perforated gastric ulcer surgical intervention is indicated.

The operations hitherto suggested or performed in nonperforated ulcer consist in opening the stomach and excising or cauterising the ulcer with or without pylorectomy and gastro-jejunostomy. I have found no record of any surgical measure for dealing with hæmorrhage following operation for perforated ulcer, but I submit that $(a)$ temporary enterostomy such as was performed in Case 3 and might well

3 Brinton: Ulcer of the Stomach.

a Brit. Med. Jour,, vol. ii., 1897, p. 544. 4 Ibid., vol. ii., 1898, p. 1407.

Te The March 2nd, 1895.

7 Ibid., p. 88 Ibid., p. 86 
Whave been performed in Case 1 has this advantage, that when life is threatened by hæmorrhage from gastric ulcers, whether perforate or non-perforate, though enterostomy be not of itself a faultless or a curative measure, it offers nevertheless an alternative between a comparatively slight operation and a severe one and may enable us to sustain life during the critical period by feeding the patient while the stomach rests. The operation may be performed in non-perforated cases somewhat as follows. The abdominal incision is made with the centre level with the umbilicus or a little lower, $3 \mathrm{~cm}$. from the middle line, $10 \mathrm{~cm}$. in length, more or less, through the left rectus muscle. Push up the great omentum and the transverse colon. Slide the fingers along the lower surface of the transverse meso-colon to the spinal column and feel for the ligament of Treitz which is the guide to the commencement of the jejunum. Open the bowel about 1 metre or less from its commencement, avoiding risk of strangulation from taking a small loop, with a small sharp tenotomy knife so that a good sized Jacques catheter may be tightly grasped without leakage. Care should be taken to avoid a sharp spur by stitching the bowel above and below not too close to the opening or food may escape when feeding by the mouth is commenced. Adequate room should be allowed for the transverse colon in its normal position. The catheter passed into the rectal end of the jejunum may be stitched to the skin as well as to the Keith's dressing to avoid risk of displacement.

Reverting to cases already the subjects of operation such as Case 1 where food passed out immediately from the stomach through a gastro-cutaneous fistula or Case 3 where hæmorrhage occurred, few surgeons could confidently hope that patients in similar conditions would survive a second operation such as excision of the ulcer with or without gastro-jejunostomy. For these a temporary enterostomy as performed in Case 3 appears to be a reasonable surgical alternative to adopt. In such cases, however, choice of the site of incision may be limited owing to the presence of unhealed or septic wounds in the middle line. Where adhesions are absent at the site of incision a thickwalled portion of small intestine should be drawn out to ascertain that the future opening be not much within 1 metre either of the ileo-cæcal valve or of the commencement of the jejunum. If dense adhesions be present any guide (whether to the relative part of the small intestine to be opened or to its gastric or rectal extremity) might be entirely absent without employment of injudicious interference. The operator might then have to be content to open the most suitable portion of small gut presenting and to pass the tube a short distance only within its lumen. Under whatsoever condition the operation has been performed at a subsequent period the bowel should be released from its abdominal adhesions if pregnancy is likely to occur.

I come now to the consideration of retro-gastric subphrenic abscess as a complication following the operation suggested but happily absent in Case 2 . Some time ago the question was raised in this society ${ }^{9}$ whether in cases where the cavity of the stomach could not be examined through the rent in a perforated ulcer on the anterior wall it might be well as a safeguard to ascertain the condition of the posterior wall through an opening in the omentum. I would go further than this and say that in all operations for perforated ulcer the lesser cavity of the peritoneum should be opened at the time of operation and for two important reasons. The first is, as suggested, for ascertaining the condition of the posterior surface of the stomach, because if we find that there is decided evidence of disease here especially if implicating the pyloric end, after closing any ulcer we should more often go on to perform a gastro jejunostomy than be content with only closing the ulcer. The second reason is that only by opening the lesser cavity and passing in the nozzle of the irrigator can this sac of the peritoneum be thoroughly flushed. The lesser cavity is well known to be a favourite site for subphrenic abscess when an ulcer affects the posterior wall of the stomach, but in the last fatal operation for perforated gastric ulcer which I saw death was due to an abscess in this situation, though there was only a single ulcer on the anterior wall which had perforated. Pus, as shown at the necropsy, had formed here, the foramen of Winslow was closed by adhesions; no recent general peritonitis existed, but both lungs were affected with extensive suppurative pleuro-pneumonia which was the immediate cause of death. The perforating

9 Proceedings of the Brighton and Sussex Medico-Chirurgical Society, 1897-98. See Mr. T. Jenner Verrall's Clinical Note, THE LANCET, Des. 17th, 1898 . ulcer on the anterior wall which had been closed by the operation was watertight and there was no other ulcer in the stomach, as I have said, to produce the subphrenic abscess. There can be no reasonable doubt, I think, that particles of the gastric contents had found their way from the greater cavity into the lesser, either before the operation or at the time of it, forced through the foramen of Winslow by the irrigating fiuid.

Do not consider that $I$ wish for a moment to adrocate sponging in preference to irrigation for cleansing the peritoneum. I advocate irrigation but I contend that although the neglect to cleanse the lesser peritoneal cavity after operation for gastric ulcers has been often unattended with bad results this is a good fortune which should not be relied upon and that the lesser cavity of the peritoneum should be flushed as thoroughly as is the greater. Why has no notice been taken hitherto of the condition of the lesser cavity? Perhaps we may explain the omission in this way-that in many cases of general peritonitis following appendicitis, salpingitis, or other causes, effusion of pus or other septic fluid occurs in the lower part of the abdomen or about the pelvis and is not of great quantity ; general peritonitis begins and the foramen of Winslow is closed by adhesions, thus shutting: off the lesser cavity, just as we find in the converse condition when gradual leakage into the lesser cavity follows a gastric ulcer on the posterior wall general peritonitis does not ensue because the foramen closes. But in the case of a perforated anterior gastric ulcer the gastric contents have only to trickle round the right free border of the lesser omentum and both the greater and the lesser peritoneal cavities are practically simultaneously soiled. The lesser cavity of the peritoneum can be opened either through the layers of the great omentum or of the transverse meso-colon, preferably through the former. Division of the lesser omentum in part, though desirable sometimes when dealing with ulcers on the lesser curvature, does not give such convenient access to the lesser cavity.

Brighton.

\section{TWO CASES OF CASAREAN SECTION.}

BY JAMES BRAITHWAITE, M.D. LoND., M.R.C.S. ENG., OBSITENRIC PHYSICIAN AND SURGEON TO THE LEEDS GENERAL INELRAIRY; EDITOR OF THE " RETROSPECT OF MEDICINI," ETC.

CASE 1.-In May, 1897, I was called upon to operate in a case of pregnancy at full term in which the pelvis was blocked by an ovarian tumour so that delivery was impossible. Labour was threatening but it had not actually commenced. When the peritoneal cavity was opened the uterus was seen to be of a darkish blue colour, probably owing to the placenta having its attachment anteriorly. The uterus was rapidly opened by a scalpel which at the same time divided the placenta; the incision, however, was completed by the use of strong scissors. The hæmorrhage was very great but was controlled by pressure with the fingers by Mr. Knaggs who ably assisted me both in this case and in the second case and to whom I must tender my grateful thanks. The child was brought out by the head and the membranes and placenta were brought out immediately afterwards. The time from the commencement of the incision to the complete emptying of the uterus would not be more than five minutes. The finger was passed through the cervical canal which was found to be sufficiently open for drainage purposes. A sponge wrung out of hot boric lotion was put into the uterine cavity and one or two very large ones (also hot) were placed around and pressed upon the uterus which was now lifted out through the abdominal wound. No elastic ligature was used around the neck of the uterus. The wound in the uterine wall was closed by silkworm-gut sutures placed deeply at $\frac{1}{2}$ in. intervals. These just missed the internal surface of the uterus. As it was noticed that the peritoneum was extremely loose and moveable owing to its not contracting in the same way that a muscular organ is capable of doing it was sewn over by a continuous catgut ligature. The original silkworm-gut ligatures were thus completely buried. The ovarian tumour was then removed in the ordinary way. The child was living and $I$ hear that it is at present in good health. The mother made an uninterrupted recovery.

CASE 2.--This patient I saw first with her medical attendant, Mr. Spong of Leeds, at her own home, but she 